W08-23

\title{
BUILDING TRUST TO SOLVE COMMONS DILEMMAS: TAKING SMALL STEPS TO TEST AN EVOLVING THEORY OF COLLECTIVE ACTION
}

\author{
Elinor Ostrom \\ Workshop in Political Theory and Policy Analysis \\ Indiana University \\ Center for the Study of Institutional Diversity \\ Arizona State University
}

(C) 2008 by author

Forthcoming in Games, Groups, and the Global Good, ed. Simon Levin. New York: Springer.

An earlier version was presented at the symposium on "Games, Groups, God(s), and the Global Good” held at Princeton University, October 4-6, 2007, and for Tanner Lecture at the University of Michigan, November 2, 2007. The support of the MacArthur Foundation and the National Science Foundation is gratefully acknowledged. I deeply appreciate the wonderfully helpful comments by Giangiacomo Bravo, Marco Janssen, Simon Levin, Tun Myint, Claudia Pahl-Wostl, and James Walker, and the excellent editing by Patty Lezotte.

\section{Workshop in Political Theory and Policy Analysis}

Indiana University, 513 N. Park Avenue, Bloomington, IN 47408-3895 USA

phone (812) 855-0441 fax (812) 855-3150 workshop@indiana.edu www.indiana.edu/ workshop 


\title{
Building Trust to Solve Commons Dilemmas: Taking Small Steps to Test an Evolving Theory of Collective Action
}

\author{
Elinor Ostrom
}

Problems of the commons exist in a wide variety of settings ranging in size and complexity from the family (e.g., the household budget and the kitchen sink) to the global scale (e.g., loss of biodiversity and global warming). Game theory is a useful theoretical tool for representing a simplified, core social dilemma facing a set of individuals sharing a commons. Game theorists, who assume that individuals base decisions on immediate returns to self, frequently use the Prisoners’ Dilemma game to represent the problem of the commons (Alcock and Mansell 1977; Richards 2001; but see Cole and Grossman 2008). The individuals in such a game are assumed to have complete information about the strategy space they face and the outcomes that will be obtained depending on their own and others' actions. On the other hand, the pure theory is about individuals who do not know one another, do not share a common history, and cannot communicate with one another. In this model, game theory predicts that individuals jointly using a commons will overharvest, leading to Hardin’s (1968) “Tragedy of the Commons.”

An important asset of game theory is that it provides a clear theoretical prediction that can be tested in carefully designed, laboratory experiments (Gardner and Ostrom 1991). When a set of anonymous subjects makes decisions without communication about appropriation from a one-shot or finitely repeated, common-pool resource in a laboratory setting based on Gordon’s (1954) bioeconomic theory, they behave broadly as game theory predicts (Ostrom et al. 1992; Ostrom et al. 1994). They overharvest. In fact, they overharvest on average even more than predicted, even though there is considerable heterogeneity in the decisions of individual subjects. 
In a new experimental design that represents a more complex resource, where subjects can make many more harvesting decisions than in earlier experiments, participants still overharvest dramatically on average when they cannot communicate (Janssen et al. 2008; Janssen and Ostrom forthcoming).

Individuals in a wide diversity of field settings also overharvest as conventional game theory predicts. Ocean fisheries provide a clear example of rampant overharvesting (Berkes et al. 2006; Myers and Worm 2003; Pauly et al. 2002; Clark 2006). Deforestation in many countries also reflects massive overharvesting (Kaimowitz and Angelsen 1998; Rudel 2005; Moran and Ostrom 2005; Ostrom 2008). Overharvesting of resources, biodiversity loss, and global warming all tend to reinforce the belief that game-theoretical predictions of the outcomes from commons dilemmas_especially for large groups of anonymous users_-are correct.

This is, however, not the end of the story. Making one simple change in the design of a laboratory experiment, allowing participants to engage in face-to-face communication (cheap talk), enables them to reduce overharvesting substantially (Ostrom and Walker 1991). Game theory predicts that individuals who have only self-regarding preferences will not change their behavior as a result of cheap talk alone. When given a chance to communicate, most subjects first try to figure out what is the best joint strategy. Subjects, who are most successful, use communication to help build a group identity and commitment to follow their agreed-upon strategy (Simon and Schwab 2006). Behavior changes dramatically and subjects greatly increase their joint payoffs. Sally (1995) has undertaken a meta-analysis of 35 years of published experiments on PD games and found that discussion among the subjects significantly influences the rate of cooperation in repeated experiments. Communication also enables some subjects to 
develop ingenious strategies to use attributes of their environment to achieve high returns (Janssen and Ostrom forthcoming).

Further, when given opportunities for engaging in costly punishment, subjects punish others who continue to overharvest - contrary to game-theoretical predictions based on a model of the individual with only self-regarding motives (Ostrom et al. 1992). Multiple studies have now found that individuals facing dilemmas are willing to sanction those who do not cooperate as well as punish out presumed retribution (Falk et al. 2005; Henrich et al. 2006). Further, when given an opportunity to devise their own sanctioning rules, those who adopt their own rules tend to follow these rules closely, achieve higher joint returns, and the use of punishment drops to almost zero (Ostrom et al. 1992). Parallel to laboratory findings, field researchers have recorded a large number of empirical settings where those directly involved in a commons have themselves devised, adopted, and monitored rules over time that have led to robust common-pool resource institutions (McCay and Acheson 1987; Ostrom 1990; NRC 1986, 2002; Dietz et al. 2003; Dolšak and Ostrom 2003; Acheson 2003; Coleman and Steed 2008; Schlager and Ostrom 1992; Ghate et al. 2008; Shivakumar 2005; see also Janssen and Ostrom 2006).

\subsection{A Theoretical Puzzle}

Why do individuals conform to the game-theoretical predictions based on self-regarding motives in some social dilemma settings, but not in others? A frequent answer to this question is that the context of the situation makes a difference as to whether individuals cooperate to solve social dilemmas or simply pursue short-term material interests. But what does the "context of a situation” mean? What contextual factors change the way humans behave? If this were a minor puzzle, it would not be worth devoting a major effort to its analysis. Given the harm that individuals can bring to small- and medium-sized social and ecological systems as well as to the 
global commons, the effort to untangle this puzzle is worth substantial effort! And substantial effort will be required to untangle this puzzle at multiple scales ranging from small groups in a laboratory experiment to large populations sharing common-pool resources.

A central problem is that human behavior is heterogeneous even in extremely simplified experimental laboratory settings. As has been known for some time, not all subjects in a finitely repeated PD game defect (Lave 1965; Rapoport and Chummah 1965). Further, some subjects in a finitely repeated PD game mutually cooperate. Axelrod $(1984,1986)$ helped to sort out how this could happen. As Axelrod established, if individuals adopt a "tit for tat" strategy of cooperating on the first move and then copying what the other player does on future rounds, players may get out of the trap of "always defect" leading to lower payoffs for both. This practical strategy—and its many useful variants—does not, however, guarantee mutually productive outcomes. If one player defects on the first round of play (or thereafter), they may again be trapped in a series of mutual defections. Further, tit-for-tat is not effective in larger groups.

Puzzling over the diverse findings from social dilemma experiments, some researchers focused on an even simpler game than that of a two-player PD game- the Dictator game-in an effort to try to understand individual behavior in an even simpler setting (Güth and Huck 1997). In Dictator experiments, one subject is allocated a fund that they can share with another unknown second subject, or keep all of it for themselves. Scholars have again been surprised by the variety of actions taken by subjects given this limited structure. Some subjects keep all of the funds initially allocated to them, as predicted by self-regarding game theory. Others share a varying portion with the unknown second player, but usually not more than half of the initial 
allotment (Bohnet and Frey 1999; Eckel and Grossman 1996; Hoffman et al. 1996; Frohlich and Oppenheimer 1992; Burnham 2003).

Another very simple social dilemma experiment with puzzling outcomes is the "Investment Game,” which is also referred to as the "Game of Trust.” In the regular form of this game developed first by Berg, Dickhaut, and McCabe (1995), one player is assigned the position of "first mover." The first mover is assigned a private endowment that they can either keep or allocate to an anonymous second mover. In the standard game, the first player makes a decision that can create a joint surplus to be shared with the second player because each $\$ 1$ sent to the second mover by the first mover is tripled by the experimenter. The second mover is not known to the first player (nor, when double-blind procedures are used, to the experimenter). The dilemma is that to create the larger joint pool, the first mover must either trust that the second mover will reciprocate the first mover's generous transfer or, potentially have preferences that positively weight the second mover's payoff (Cox 2004; Cox and Deck 2005).

The self-regarding, game-theoretical prediction for this design is that the first player will send no funds to the second player since they will predict that the second player will return zero funds to them. In the first experiment on the Game of Trust, Berg and colleagues (1995) were surprised to find that a substantial proportion of first movers sent funds to the second movers. Only two of the first movers followed the game-theoretical prediction of sending nothing, and many of the second movers returned funds to the first player. This experiment has been replicated extensively by scholars across the world (see Cox et al. forthcoming and extensive cites therein). Substantial heterogeneity of individual behavior was found even within this extremely simplified experimental setting. The findings vary from setting to setting, but rarely provide strong support for the game-theoretical prediction (Faysse 2005). 
Thus, a core puzzle that we face in thinking about Games, Groups, and the Global Good is that scholars find an immense variety of outcomes in the experimental lab and in the field rather than conformance to theoretical predictions based on a model of the individual who maximizes own short-term interests (see Bowles 2008, who reviews evidence from more than forty laboratory experiments conducted by scholars from all parts of the world that challenges the presumption that humans seek only material benefits for self). As a researcher who has used multiple empirical and theoretical methods to try to understand how groups of individuals can overcome commons dilemmas, I have learned that no single variable has the same effect in all settings. Sometimes increasing the size of a group (within a range) has a positive effect on levels of cooperation (Agrawal 2000; Agrawal and Goyal 2001; Isaac et al. 1994) and sometimes a negative effect (Richards and Andersson 2001; Poteete and Ostrom 2004; Diekmann 1986). Sometimes assigning assured property rights to a resource leads users to adopt long-term strategies that are consistent with sustaining a resource (Blomquist 1992). In other settings, assigning private property rights leads to accelerated harvesting (Mwangi 2007). Sometimes repeating a situation has a positive effect (when participants know with whom they are interacting), and sometimes a negative effect (contributions in repeated public good games fall off over time in repeated games without communication) (Isaac and Walker 1998). Heterogeneity within groups also generates positive, neutral, or negative impacts on levels of cooperation (Baland and Platteau 1996, 1999).

\subsection{The Challenges Ahead}

Thus, we face immense challenges in an effort to move beyond the "tragedy of the commons" theory that has dominated the thinking of both scientists and policymakers since Hardin’s (1968) dramatic article in Science. We now know that individuals who find themselves in social 
dilemma situations vary immensely in the behavior they adopt and subsequently in the outcomes they obtain. A major challenge is building a more general theory of individual behavior that helps us understand the vast heterogeneity in behavioral patterns and outcomes obtained by individuals facing other social dilemmas.

In my own effort to start developing an alternative "behavioral theory of collective action” (Ostrom 1998, 2003), I posited that building trust among participants that the other participants are trustworthy and reciprocators is an essential core of future theories (see Figure 1). Without the development of trust and reciprocity, those who cooperate in dilemma settings may be "suckers" who contribute to the unearned benefits of others. It is not easy, however, to use the conventional game-theoretic model of individual behavior to explain reciprocity and trust. To move ahead in understanding commons dilemmas (as well as other social dilemmas), it is important to recognize that the innards of the human animal are more complex than represented in self-regarding game-theoretical models (Fehr and Gintis 2007).

(Figure 1 about here)

A second major challenge also relates to broadening our theoretical lenses at a level above that of individual decision making. Many theoretical models of resource systems rely on simple stick-figures to represent a bioeconomic model of a resource system, but this is rarely a rich enough representation to be the foundation for effective solutions (Clark 2006: 15). We must learn how to think about social-ecological systems as complex adaptive systems (Levin 1999; Folke et al. 2005) and develop a coherent way of representing them building a common language across the social and ecological sciences for analyzing the immense number of nested variables that affect the structure of a commons or other situations in which individuals find themselves. It is somewhat reassuring to see that a growing number of ecologists and social 
scientists are now working together in a series of efforts to build more cumulative work on complex and adaptive social-ecological systems (Gunderson and Pritchard 2002; Adger and Jordon 2008). ${ }^{1}$ This second challenge is, however, beyond what I can effectively tackle in this chapter but I have addressed it in recent work (Ostrom 2007). Thus, I will focus my attention on the first challenge of building a better microtheoretical understanding of human decisions in dilemma settings.

\subsection{The First Challenge}

The self-regarding model of individual choice has been a powerful engine of theoretical predictions in a variety of contexts. It continues to be a useful model in highly competitive situations. It is a close theoretical cousin to the maximization of fitness that underlies biology (Maynard Smith 1982; Maynard Smith and Szathmáry 1997). The challenge is to develop a theoretical approach for analyzing individual preferences outside of highly competitive environments that does not deny the usefulness of the self-regarding model in competitive settings (Satz and Ferejohn 1994). This challenge is one that a number of researchers are tackling (Cox 2004; Cox et al. 2007; Bolton and Ockenfels 2000; Fehr and Schmidt 1999). Fortunately, we can build on developments in behavioral game theory where scholars are broadening the model of the individual used in self-regarding game theory (Camerer 2003; Camerer and Fehr 2006).

\subsubsection{A Core Set of Assumptions about Human Behavior}

In light of extensive field and experimental research, I have come to use a basic set of assumptions about individual human behavior in diverse contexts. These include:

1. Humans make decisions within diverse domains of decision-making units that extend from small groups, to communities, to nations, to international organizations. 
2. Within all decision-making domains, fallible individuals make decisions that are intended to increase net benefits to themselves and potentially to others, but at times at the expense of others.

3. Individuals learn from their experiences within a particular domain and from culturally transmitted experiences about the effects of their joint actions on particular resources.

4. Human decisions in all domains are affected by whether they share preferences and goals with others involved, the assets they posses, the information they obtain, the incentives and disincentives they face, the internal learning and choice processes used, and the time horizon invoked.

5. Individuals may adopt norms of behavior, such as "cooperate with others who cooperate with you" or "be trustworthy," in domains where individuals interact repeatedly with others and/or gain information about their past behavior.

6. Decisions at any one domain affect the information, incentives, and time horizon (and, perhaps the cultural values, resources, internal choice processes, and time horizon) of others in that domain, at present and future time periods, and sometimes at other tiers.

7. Human choice is interdependent within tiers and across time and space. Impacts may be horizontal, upward, and downward.

8. Physical and biological processes also affect the information, the incentives, and the time horizon that are used in human choice as well as being affected by human choice.

These assumptions are broader than needed to explain specific behavior in a highly structured setting, but I prefer to use a general set of underlying assumptions that do not need to be changed extensively to fit particular settings even though specific behavior varies from setting to setting. In a highly competitive situation, the above assumptions are consistent with using a theory of individual maximization of expected material values to self, as Adam Smith long ago recognized (Alchian 1950). But as Smith himself also recognized, individuals who interact with one another in other settings may develop broader sets of preferences than just their own immediate material well being - and they may actually do better as a result of their broader preferences. 


\subsubsection{Focusing on the Fifth Assumption: The Possibility of Adopting Norms}

Most of the eight assumptions laid out above related to a broader theory of human behavior nested in linked domains of interaction are not controversial. Nor can we use them to make specific predictions of how people will behave in a particular context since they are very general. Assumption 5-related to the possibility of humans adopting norms-is a crucial assumption for developing an alternative theory of human behavior that can be used to explain outcomes in competitive situations as well as in a variety of social dilemma situations. The fifth assumption is more controversial than the other seven assumptions listed above. Scholars using selfregarding game theory would not make this assumption. Nor would they need it when modeling highly competitive market settings. It would be hard to explain cooperation in social dilemma situations, however, unless humans have the basic capabilities to adopt norms of behavior that may lead them at times to adopt costly strategies that are not in their short-term material advantage (even though such norms are frequently in their long-term net benefit).

In Crawford’s and my efforts (1995/2005) to analyze why individuals follow norms of behavior (such as telling the truth, being trustworthy, and using reciprocity), we posited the addition of a delta parameter to the preference function that represented the costs and benefits of following a norm that individuals felt they must or must not do. The function could take on a positive value that would reflect the pride that an individual felt when following a norm or a negative value to represent the shame when breaking a norm. The growing evidence from neuroeconomics that some individuals gain real pleasure from following norms such as trusting and trustworthy behavior is consistent with our effort to include overtly the concept of norms in the preference functions of individuals (Rilling et al. 2002; McCabe and Smith 2001; Fehr et al. 2005) and even from punishing violators of social norms (de Quervain et al. 2004). Further, the 
work in evolutionary game theory (Axelrod 1986; Gintis 2000; Skyrms 1997; Boyd et al. 2003), cultural evolution (Boyd and Richerson 1985), and the relationship between biological and cultural evolution (Ehrlich and Levin 2005) provides a coherent explanation for how delta parameters may have evolved.

Assuming that some individuals may learn to adopt and use norms of trust and reciprocity substantially alters the way one thinks about social dilemmas. Norms of reciprocity involve returning positive actions with positive responses and negative actions with negative responses. If individuals do not believe that the others with whom they are relating are trustworthy, then the best they can do is to act in a manner consistent with accepted theory of self-regarding preferences. On the other hand, if individuals trust that at least some others will reciprocate cooperation with cooperation, then it may pay—especially in settings where the costs are not too high initially—-to explore this possibility by trying cooperative actions and seeing what happens. If others do not reciprocate, one immediately returns to noncooperation and tries to exit and find other situations that are more productive (Axelrod 1997; Axelrod and Cohen 2000). If others do reciprocate, it may be possible to achieve substantial long-term benefits. Once such a pattern is initiated, gaining a reputation for being trustworthy and reciprocating cooperation is an asset that can increase individual-level outcomes (as well as increase joint returns) (Ahn and Ostrom 2008).

Assuming that individuals may invest in a reputation for being trustworthy, can gain trust, and can use reciprocity, does not automatically lead to more optimistic predictions in regard to the provision of public goods and the regulation of common-pool resources. It does, however, refocus the analysis from an assumption that individuals are hopelessly trapped in a situation from which they cannot extract themselves without an external authority deciding what 
should be done and imposing that decision on participants. Asking what "the" government should do assumes that external actors will always come up with wise decisions and implement them effectively and fairly. The perspective of this chapter leads the analyst to inquire how individuals facing commons problems can gain trust that others are trustworthy and that a cooperator will not be a sucker who contributes while others continue to free ride.

\subsubsection{Unpacking How Context Affects Trust and Reciprocity}

In earlier efforts to explain the varying levels of cooperation observed in the field and the laboratory, I developed a relatively simple framework in my Presidential Address to the American Political Science Association and then revised it in a book that James Walker and I edited on Trust and Reciprocity (Ostrom 1998, 2003). Figure 1 focuses in on a core set of relationships that characterizes any repeated social dilemma. An individual may cooperate simply from their own norms, but learning the reputation of others increases trust that their own efforts to initiate reciprocity and cooperation will lead to higher cooperation and net benefits.

Figure 2 adds two elements. First, I posited that attributes of biophysical variables (such as those characterizing a resource system), attributes of a community (such as those related to shared norms and sense of common history and future), and institutional variables (related to the rules used to structure relationships) impact on the core set of relationships. ${ }^{2}$ Second, I posited that feedback relationships among the variables would strengthen or weaken the levels of cooperation over time. The framework was intended to stimulate further theoretical development beyond narrow assumptions regarding human behavior and to be able to explain behavior in different, simple contexts as well as the more complex contexts in the field where attributes of resources, culture, and institutions have a big impact.

(Figure 2 about here) 
This effort to begin to "unpack" the meaning and components of "context" helps to explain the variability of behavior observed across social dilemmas. In some social dilemma contexts, one should expect low levels of cooperation. In a lab setting where (1) the resource is a finitely repeated common-pool resource experiment, (2) the cultural setting is minimal because the subjects identities are unknown to each other and no communication is allowed, and (3) the “institution” involved is open access, one should predict, as Hardin did years ago, that most participants will overharvest. As discussed above, this is what is found in the lab under controlled settings. When we made a minor change to the institutional rules of our experiments to allow repeated communication, without changing the other contextual factors, individuals used the opportunity to work out joint strategies to improve their outcomes and to chasten one another if information about aggregate harvesting levels indicated that one or more individual had broken a verbal agreement (Ostrom et al. 1992).

It is a repeated finding that when institutional rules are changed to allow communication in a social dilemma, while holding other contextual variables constant, subjects use the opportunity to elicit norms, assess each others' trustworthiness, and increase cooperation rates (Sally 1995). Bicchieri (2002) evaluated two possible explanations for the effectiveness of communication in a review of experimental studies of social dilemmas and concluded that communication was more important in eliciting social norms than in simply building group identity. Related to eliciting social norms, several experimental researchers have examined to what extent subjects in dilemma situations are able to assess the trustworthiness of others (Hayashi and Yosano 2005; Cosmides 1989). Humans appear to have a high level of "social intelligence.” Those who have participated in some form of communication with one another in 
a controlled laboratory setting do gain a relatively accurate judgment of the likelihood that others in an experiment will be trustworthy or not (Yamagishi and Kosugi 1999; Kikuchi et al. 1996).

\subsubsection{Some Small but Important Steps to Understand the Impact of Specific Contextual Variables on Cooperation}

A recent study tests the core relationships among participants posited in Figures 1 and 2 for “predicting” results of new experiments. Ebenhöh and Pahl-Wostl (2008) provide further evidence that the level of cooperation in a social dilemma—even in experiments without communication — depends on attributes of the context of a situation that encourage or discourage the development of norms, such as reciprocity, and their sustainability in repeated situations. Ebenhöh and Pahl-Wostl used data from a series of one-shot Dictator games (Hoffman et al. 1996; Güth and Huck 1997) and a set of Games of Trust (Berg et al. 1995; Cox 2004) in an Agent-Based Model (ABM) intended to generate individual agent behavior related to the amount of funds sent to a second subject by a "dictator" in the first type of game and by the "trustee" in the second type of game.

As mentioned above, in Dictator experiments, the first subject is allocated a fund that they may (or may not) share between themselves and a second player who is unknown to them and makes no decisions. Ebenhöh and Pahl-Wostl find that the subjects in settings with the highest anonymity—achieved through double-blind procedures—allocated the least amount to the second subject (Hoffman et al. 1994). In such a setting, only individuals with strong internal norms would give funds. Nothing in the context would motivate them otherwise. Levels of anonymity vary across Dictator experiments conducted by different scholars and affect behavior (Frohlich and Oppenheimer 2000; Frohlich et al. 2001). While the identity of the specific individual assigned the second position is not revealed to the first player in all these experiments,

some scholars do not use double-blind procedures. Without double-blind procedures, the person 
assigned to hold the Dictator position could potentially worry that a decision to keep all of the funds would adversely affect the evaluation made of them by the researcher who would know their identity. Further, one set of Dictator experiments was conducted in a school where subjects knew that the other participants were from their own school even though they did not know specifically who the other person was (Güth and Huck 1997). Ebenhöh and Pahl-Wostl found that as the assurance of anonymity was lessoned across diverse experiments, from the doubleblind experiment to an experiment conducted in a school, the average fund allocated by the subject assigned the Dictator position to the unknown "other player” rose systematically.

Ebenhöh and Pahl-Wostl then examined how much the initial act by a first player in a Game of Trust influences a second player's decisions. They reasoned that the second player is making a decision about allocating funds to the first player, which is similar to the decision made by the first player in a Dictator game. This enabled them to investigate the additional effect of the reputation for cooperation that the first player gains in a Game of Trust as a result of the amount of funds (including no funds) they decide to allocate to the second player. Does the initial "investment" of the first player and their subsequent reputation affect the level of reciprocity extended by the second player? Ebenhöh and Pahl-Wostl answer positively.

As shown in Figure 3, Ebenhöh and Pahl-Wostl modified the core section of Figure 2 to represent the relations they posited among the individual-level variables in their ABM. They added two additional norms of being fair and being cooperative to the norm of reciprocity that I had posited. Then, they ran their ABM to assess its power for predicting the results from five sets of Dictator experiments and two sets of Trust experiments. Their model helped to explain the different outcomes across experiments. Agents, who hold initial, but not necessarily strong, commitments to a set of norms, find added strength in basing costly actions on those norms 
depending on the specific structure of the situation in which interactions occurred. In experiments where anonymity was fully protected and no chance to build a reputation, the level of cooperation is lowest. They concluded that "cooperation is highest, if considerations based on fairness, on reciprocity, and on cooperativeness suggest the same behavior” (2008: 246). They describe their approach as "looking at decision processes in very small steps," so as to "abstract more complicated decision situations and simplify them step by step. The simple decisions can be building blocks from which more complex decision mechanisms are made up. . .” (2008: 247).

(Figure 3 about here)

Boero et al. (2008) have also taken a recent “small” but important step to test how small changes in the contextual structure of a repeated two-person Game of Trust affect outcomes. Keser (2003) had earlier shown the importance of reputation in a repeated game where the first mover posted a rating of the second mover after receiving the funds (if any) returned by the second mover. Boero and colleagues designed two experiments to push Keser’s findings still further. In the first ten rounds of both experiments, players were anonymously shifted in terms of their position as Trustor or Trustee as well as with whom they were paired. In the first experiment, they divided the groups into three designs: (Design 1) the first mover made a public rating of the second mover after receiving funds, (Design 2) the second mover made a public rating of the first mover after receiving funds, and (Design 3) both players rated each other after receiving funds. In the first experiment, the ratings that had been made about one subject were told the other subject before that subject made a decision. Boero and colleagues found that significantly larger amounts were sent by the player being rated in the first and second designs and by both players in the third design than in the first ten rounds of this experiment. 
In their second experiment, the researchers revealed information about ratings only after a subject had made a decision to invest or to return funds (rather than before as in the first experiment). The second experiment thus removed the incentive to invest in reputation so as to gain immediate financial returns, since ratings could no longer influence the decision of the other subject. Boero and colleagues found that first and second movers invested in reputation in both experiments by sending significantly more funds when they were rated as contrasted to the rounds when they were not rated. In the first experiment, one could explain the investment in reputation solely by the significantly higher incomes obtained. The second experiment provides evidence that individuals invest in their own reputation when an opportunity to do so is present, even if it does not lead immediately to higher monetary returns.

Colleagues in Colombia have conducted a series of 64 common-pool resource experiments in rural villages to assess the impact of telling subjects that a choice leads to optimal results and backing this with the imposition of either a high or a low fine assessed if a subject chosen randomly did not follow the prescribed rule (Rodriguez-Sickert et al. 2008). The structure of the experiment is similar to those conducted earlier at Indiana University (Ostrom et al. 1994). In a series of eight, five-person, common-pool resource experiments, they found that when the villagers were presented a simple game with no institutional structure—an open access game - they overharvested substantially, as had been found in earlier experiments.

Rodriguez-Sickert and colleagues then explored the effect of three designs. In all of these designs, the experimenter told the subjects the optimal harvesting strategy for the mathematical structure of the resource. In fourteen experiments, they imposed a high fine on a subject caught extracting more than the prescribed optimal. In another set of twenty-five experiments, they imposed a low fine on those discovered not to be following the recommended 
harvesting level. (Subjects were selected randomly to be monitored and the fines were imposed privately so that who had broken the rule was not revealed to others.) The experimenters found that behavior improved substantially when fines were established but that subjects did not fully achieve the recommended optimal. To their surprise, they found no difference between the experimental results from the high-fine design as contrasted to the low fine. The latter finding was quite surprising in that the fine was so small as to not affect final payoff substantially.

In a third design, they allowed subjects to vote on whether they would adopt a fine or not. Those who voted against adopting a prescribed amount of extraction and imposing a fine for breaking the prescription did better on the first few rounds after the decision, but rapidly returned to the level of overharvesting as they had done before the vote. Those who voted for the fine did about the same as the subjects in experiments when the optimal-level prescription was imposed from outside. This goes back to the problem of trust and reciprocity. If people do not trust that others are following a rule or a moral norm, they will tend to stop following them themselves. In an earlier fourth design where subjects were given an opportunity for face-to-face communication, Cárdenas et al. (2000) found that subjects used this opportunity to cajole each other into adopting and following close to an optimal strategy.

Rodriguez-Sickert posit that being told the optimal extraction, and either having a fine imposed for not doing the optimal or enabling communication among rounds, was a way of establishing a moral sense that this was what they "should" do. The size of the fine did not affect the moral impact of being told that they should all do X especially when they found that moving toward doing $X$ was a very substantial improvement.

In future work, I plan to return to further development of the framework that led to the above figures. In this chapter, I have focused more on attributes of institutions that affect the 
structure of an experiment and the observed norm-related behavior. I have not discussed much about attributes of resource systems and communities that I also see as affecting the context, even though these are discussed extensively in Ostrom (1990, 2005). I thought it was essential in a book that is focusing on games and the common good to synthesize some of the core experimental research conducted by other scholars on social dilemmas that strongly support Assumption 5 above. At this point, I hope the reader agrees that it is no longer controversial to assume that individuals may adopt norms of trustworthiness and reciprocity depending on specific attributes of a situation.

\subsection{What are We Learning about Norms and the Context of Social Dilemmas?}

In the introduction, I posed a "theoretical puzzle" for those interested in Games, Groups, and the Global Good: Why do individuals conform to the self-regarding game-theoretical predictions regarding behavior in social dilemmas in some situations but not in other situations? While a complete answer to this question is not provided in this chapter, we can move ahead of sheer puzzlement.

\subsubsection{What are We Learning about Norms?}

One part of a simple answer to this question is the growing evidence that human behavior does not uniformly conform to the underlying assumptions about human behavior utilized in selfregarding game-theoretical analyses. Many game theorists and policy analysts basing recommendations on these models assume that all individual behavior is self-centered and focused on maximizing short-term material benefits. In other words, they assume that individuals do not use norms in making decisions that affect material outcomes. While it is clear that the traditional game-theoretical assumption is wrong in some contexts, we cannot now assume that all individuals adopt norms of reciprocity, fairness, and cooperation at least initially 
in all repeated situations. We have to develop the fifth assumption listed above still further and build on the substantial theoretical efforts that have contributed to a broader understanding of human behavior (Fehr and Schmidt 1999; Camerer 2003; Cox et al. 2007; Crawford and Ostrom 1995/2005; Ostrom 1998).

\subsubsection{What are We Learning about the Micro Context?}

Results from extensive experimental research are generating knowledge that is now enabling us to move beyond simply claiming that "context" makes a difference. Now it is possible to identify core elements of "micro context" of a particular situation that are likely to enhance or detract from the probability that individuals will use norms of reciprocity, fairness, and cooperativeness. In regard to variables related to the context of simplified experiments that affect the core relationship identified in Figures 1-3, we are gaining considerable confidence regarding the effect of ten specific variables. In situations characterized by the union of the first three variables listed below, very low levels of cooperation are consistently observed (Frohlich and Oppenheimer 2001). Even in such settings, some individuals draw upon deeply held, personal norms and cooperate with others, even though no external pressure is expressed by others (or even feared to be expressed).

1. One-shot interactions;

2. Full anonymity — current actions taken by an individual cannot be attributed to that individual by anyone else; and

3. No information is available to one participant about the others involved.

Simply moving from one-shot to repeated experiments, while holding anonymity and lack of information constant by switching partners for every decision, does not change the prediction of minimal levels of cooperation (see Frohlich et al. 2001; Macy and Skvoretz 1998; Janssen 2008). Assumption 5 only posits that individuals may adopt norms. The likelihood of this occurring is 
decreased when individuals do not interact with others (or at least learn about the past actions of others in similar situations).

When the structure of a situation includes repeated interactions, the level of cooperation achieved is likely to increase in those contexts in which the following attributes occur:

4. Information about past actions is made available;

5. Repeated interactions occur with the same set of participants;

6. Participants can signal one another by sending pre-structured information;

7. Prescriptions are adopted and enforced that when followed do lead to higher outcomes;

8. Participants are able to engage in full communication (via writing or "chat room" without knowing the identity of the others involved);

9. Participants are able to engage in full communication with known others (via face-toface discussions or other mechanisms);

10. In addition to communication, participants can sanction (or reward) each other for the past actions they have taken; and

11. Participants can design their own rules related to levels of cooperation and sanctions that are to be assigned to those who do not follow agreed-upon rules.

The substantial number of carefully designed experiments that have been conducted by researchers in many laboratories (as well as in related field experiments) provides a solid empirical foundation for this initial list of "contextual" variables that have repeatedly been found to affect levels of cooperation. Frohlich and Oppenheimer (2000) sought to unpack the concept of context a few years ago and their unranked list has substantial overlap with the above.

\subsection{What is Next on the Agenda?}

Now that we are able to specify eleven microsituational variables that affect the probability of individuals achieving higher levels of cooperation and outcomes, we need to ask two further questions: How does unpacking the attributes that affect the "context" of a situation improve our 
more general understanding of human adoption of norms? How can we improve the likelihood of increasing cooperation related to the sustenance of common-pool resources?

Regarding our general understanding of social dilemmas, experimental and field research substantially increases our confidence in the possibility of humans using norms and the development of institutional rules to overcome or reduce the negative outcomes associated with social dilemma settings. This extensive body of research provides strong support for the assumption that individuals have an evolved capacity to adopt norms. This capacity is somewhat similar to the evolved capacity of humans to learn a language. The specific content of norms as well as the specific content of learned norms varies from culture to culture and in light of the effort of a family to instill norms in offspring. Individuals also learn that conformance to particular norms is expected in diverse types of social situations. The norms that they try initially to follow vary by types of situation: when their behavior is totally anonymous they may "cheat" on their own norms; when what they have done or who they are is known to others, they are more likely to draw on their own norms to act cooperatively in the initial rounds of interactions; if they find others to be cooperative, that reinforces their commitment to follow norms; and, if they can communicate with others about strategies and norms, they can build on each others' actions and experiences and use verbal sanctions against those who do not cooperate.

There is obviously much more to be done in the experimental lab and in the field. In the lab, we need to start adding other players who have asymmetric powers to approximate more closely some of the important field conditions present in many dilemma situations. Rarely do all of the participants using a resource have identical investment or harvesting power. Colleagues and I have started several experimental programs where we are exploring various aspects of 
asymmetrical powers in both common property and private property settings and we hope to encourage others to explore asymmetry more fully in the future. Another important development is using more complex formats in experimental designs so that the decision environments move closer to the kinds of ecological systems that exist in the field. Marco Janssen has designed several computer-based experiments that simulate plants regrowing when other plants are left around them, water flowing from upstream to downstream locations, and trees that grow at a slower rate than other resources. This research program has already produced some exciting findings and is testing some of these in field experiments (Janssen et al. 2008; Cardenas et al. forthcoming).

Now what do these developments have to do with improving the likelihood of sustaining common-pool resources in the field? As long as scholars and policy analysts accepted the narrow game-theoretic assumption that individuals maximize only individual material returns, they presumed that local users of a resource were relatively helpless and would not cooperate to solve collective-action problems. The only way to "solve" problems of the commons in this view was to impose either private property or government ownership on the users of a commonpool resource. A substantial portion of academic literature was devoted to presenting arguments in favor of specific property systems that were logically shown to lead to optimal mathematical results to solve particular resource problems. ${ }^{3}$

A change in the model of human behavior enables analysts to ask questions related to which structural variables enhance the likelihood that individuals will cooperate with each other and seek out innovative ways of solving collective-action problems fitted to a local setting (Faysse 2005; Xepapadeas 2005). Using a broader theory of human behavior, we should expect that aspects of a resource, the community in which people find themselves, and the rules that are 
being used have a big impact on whether individuals facing a social dilemma do indeed adopt norms (Ostrom 2005). We should be asking how different institutions support or undermine norms of reciprocity instead of simply presuming that central authority is necessary to enforce rules related to cooperation on participants (Bowles 2008; Frey 1994, 1997).

Understanding the importance of norms does help us to explain a repeated finding related to the kinds of sanctions used in field settings. Findings from multiple studies in many countries is that in long-surviving common-pool resources, the local users monitor the harvesting practices of the others using a resource and use graduated sanctions when they discover someone who is breaking a rule (see Hayes 2006; Gibson et al. 2005; Ostrom and Nagendra 2006; Ghate and Nagendra 2005; Ostrom 1990). Without monitoring backed up by graduated sanctions, users cannot be assured that others are following agreements. ${ }^{4}$ If some users worry that they are being a sucker while others are taking advantage of them, they are likely to adopt more self-seeking strategies and the levels of cooperation needed to sustain a resource of time that can rapidly come undone.

When humans learn to value trust and reciprocity and use them as fundamental norms for organizing their lives, it is possible for them to agree on a set of rules that they agree to follow. Thus graduated sanctions are a way of informing those, who have made an error or faced some emergency temptation, that others are watching and, if someone else were to break a rule, they would likely be observed (Ostrom 1990). With user monitoring and graduated sanctions, continuing to follow a positive norm of reciprocity is reasonable and generates higher outcomes.

\subsection{Conclusion}

As long as many scholars continue to presume that all humans are self-interested maximizers in all contexts, the importance of building trust and reciprocity among users of a commons is not 
viewed as important. What has been viewed as important for many scholars is devising optimal external rules to impose on resource users so that they will stop overharvesting from a commons. Sufficient research now supports an assumption that humans may endogenously adopt norms of trustworthiness and reciprocity in contexts where there is a higher probability that they share a common future, their actions are known or reported to others, and cooperative actions do lead to increased payoffs. This assumption makes a big difference in how one understands the microrelationship among those relying on a commons.

We must also ask serious theoretical and empirical questions about the confluence of ecological and social variables as these affect the structure of settings that produce incentives to overuse or to sustain commons. Further, we need better to understand how diversity in human motivations may have evolved over time rather than a narrowly self-interested set of preferences (Goetze 2008; Masters 2008; Levin, this volume). In addition to further development of an empirically supported microtheory of human behavior, it is also essential that social and ecological scientists begin to develop a common language that can be used to build joint theories and undertake empirical tests of the impact of the size of a resource; the type of resource units produced; and the productivity, predictability, and equilibrium properties of a resource. This will, of course, require major efforts beyond this chapter. 


\section{Notes}

${ }^{1}$ See the special feature of PNAS of September 2007, where fourteen scholars from multiple fields took a major initiative to move "Beyond Panaceas" and to help develop a framework for diagnosing problems of social-ecological systems and reduce the tendency to think that there are optimal solutions for all kinds of commons problems characterized by huge diversity in their attributes, history, productivity, and scale.

${ }^{2}$ These three broad clusters of variables are core elements used in the Institutional Analysis and Development (IAD) framework that has evolved over three decades of field research conducted by scholars associated with the Workshop in Political Theory and Policy Analysis at Indiana University. For an extended explanation of the IAD framework, see Ostrom (2005).

${ }^{3}$ For an in-depth discussion of the problems of recommending panaceas, see the special feature of PNAS mentioned in note 1 above.

${ }^{4}$ One of the more successful efforts to create a private property-rights system for inshore fisheries has been developed over time in British Columbia after some initial efforts to create rules to limit fishing rights were not successful (Clark 2006). One of the costly but important attributes of the newer system of rules that has been evolved is that there is a monitor on every boat that is recording where the boat goes, the amount of fish harvested, any by-catch that is thrown over the side of the boat, and the amount of fish sold. The monitoring system is costly, but it does appear that over time fishers have begun to see the logic of the rule system that has been developed, agree to reduce their overharvesting, and know that others are being held to follow the rule. 


\section{References}

Acheson, James. 2003. Capturing the Commons: Devising Institutions to Manage the Maine Lobster Industry. Hanover, NH: University Press of New England.

Adger, Neil, and Andrew Jordon, eds. 2008. Governing Sustainability. New York: Cambridge University Press.

Agrawal, Arun. 2000. “Small Is Beautiful, but Is Larger Better? Forest-Management Institutions in the Kumaon Himalaya, India.” In People and Forests: Communities, Institutions, and Governance, ed. Clark Gibson, Margaret McKean, and Elinor Ostrom, 57-85. Cambridge, MA: MIT Press.

Agrawal, Arun, and Sanjeev Goyal. 2001. "Group Size and Collective Action: Third-Party Monitoring in Common-Pool Resources.” Comparative Political Studies 34(1): 63-93.

Ahn, T. K., and Elinor Ostrom. 2008. “Social Capital and Collective Action.” In The Handbook of Social Capital, ed. Dario Castiglione, Jan van Deth, and Guglielmo Wolleb, 70-100. Oxford: Oxford University Press.

Alchian, Armen A. 1950. “Uncertainty, Evolution, and Economic Theory.” Journal of Political Economy 58(3): 211-21.

Alcock, James E., and Diana Mansell. 1977. "Predisposition and Behaviour in a Collective Dilemma.” Journal of Conflict Resolution 21(3): 443-57.

Axelrod, Robert. 1984. The Evolution of Cooperation. New York: Basic Books.

Axelrod, Robert. 1986. “An Evolutionary Approach to Norms.” American Political Science Review 80(4): 1095-111.

Axelrod, Robert. 1997. The Complexity of Cooperation: Agent-Based Models of Competition and Collaboration. Princeton, NJ: Princeton University Press.

Axelrod, Robert, and Michael D. Cohen. 2000. Harnessing Complexity. New York: Free Press.

Baland, Jean-Marie, and Jean-Philippe Platteau. 1996. Halting Degradation of Natural Resources: Is There a Role for Rural Communities? Oxford: Clarendon Press.

Baland, Jean-Marie, and Jean-Philippe Platteau. 1999. "The Ambiguous Impact of Inequality on Local Resource Management.” World Development 27: 773-88.

Berg, Joyce, John Dickhaut, and Kevin McCabe. 1995. "Trust, Reciprocity, and Social History.” Games and Economic Behavior 10(1): 122-42. 
Berkes, Fikret, et al. 2006. “Globalization, Roving Bandits, and Marine Resources.” Science 311: 1557-58.

Bicchieri, Christina. 2002. "Covenants without Swords: Group Identify, Norms, and Communication in Social Dilemmas.” Rationality and Society 14(2): 192-228.

Blomquist, William. 1992. Dividing the Waters: Governing Groundwater in Southern California. San Francisco, CA: ICS Press.

Boero, Riccardo, Giangiacomo Bravo, Marco Castellani, and Flaminio Squazzoni. 2008. "Reputational Cues in Repeated Trust Games.” Brescia, Italy: Università di Brescia, DSS Papers SOC 01-08.

Bohnet, Iris, and Bruno S. Frey. 1999. "The Sound of Silence in Prisoner’s Dilemma and Dictator Games.” Journal of Economic Behavior and Organization 38(1): 43-58.

Bolton, G. E., and Axel Ockenfels. 2000. "A Theory of Equity, Reciprocity and Competition.” American Economic Review 90: 166-93.

Bowles, Samuel. 2008. "Policies Designed for Self-Interested Citizens May Undermine 'The Moral Sentiments:' Evidence from Economic Experiments.” Science 320 (June 20): 1605-09.

Boyd, Robert, Herbert Gintis, Samuel Bowles, and Peter J. Richerson. 2003. "The Evolution of Altruistic Punishment.” PNAS 100: 3531-35.

Boyd, Robert, and Peter J. Richerson. 1985. Culture and the Evolutionary Process. Chicago: University of Chicago Press.

Burnham, Terrence C. 2003. "Engineering Altruism: A Theoretical and Experimental Investigation of Anonymity and Gift Giving." Journal of Economic Behavior and Organization 50(1): 133-44.

Camerer, Colin F. 2003. Behavioral Game Theory: Experiments in Strategic Interaction. Princeton, NJ: Princeton University Press.

Camerer, Colin F., and Ernst Fehr. 2006. “When Does ‘Economic Man’ Dominate Social Behavior? Science 311 (January 6): 47-52.

Cárdenas, Juan-Camilo, John K. Stranlund, and Cleve E. Willis. 2000. "Local Environmental Control and Institutional Crowding-Out.” World Development 28(10):1719-33.

Cárdenas, Juan-Camilo, Marco Janssen, and Francois Bousquet. Forthcoming. "Dynamics of Rules and Resources: Three New Field Experiments on Water, Forests and Fisheries.” In Handbook on Experimental Economics and the Environment, ed. John List and Michael Price. New York: Edward Elgar. 
Clark, Colin W. 2006. The Worldwide Crisis in Fisheries: Economic Models and Human Behavior. Cambridge: Cambridge University Press.

Cole, Daniel H., and Peter Z. Grossman. 2008. "Institutions Matter! Why the Herder Problem is Not a Prisoner’s Dilemma.” Working Paper. Indianapolis: Indiana University Law School.

Coleman, Eric, and Brian Steed. 2008. "Monitoring and Sanctioning in the Commons: An Application to Forestry.” Working Paper. Bloomington: Indiana University, Workshop in Political Theory and Policy Analysis.

Cosmides, Leda. 1989. “The Logic of Social Exchange: Has Natural Selection Shaped How Humans Reason? Studies with the Watson Selection Task.” Cognition 31: 187-276.

Cox, James. 2004. "How to Identify Trust and Reciprocity.” Games and Economic Behavior 46: 260-81.

Cox, James, and Cary A. Deck. 2005. “On the Nature of Reciprocal Motives.” Economic Inquiry 43(3): 623-36.

Cox, James, Daniel Friedman, and Steven Gjerstad. 2007. “A Tractable Model of Reciprocity and Fairness.” Games and Economic Behavior 59(1): 17-45.

Cox, James, Elinor Ostrom, and James Walker, with Jamie Castillo, Eric Coleman, Robert Holahan, Michael Schoon, and Brian Steed. Forthcoming. "Trust in Private and Common Property Experiments.” Southern Economic Journal.

Crawford, Sue E. S., and Elinor Ostrom. 1995. “A Grammar of Institutions.” American Political Science Review 89(3) (September): 582-600. Now revised as chapter 5 in Elinor Ostrom, Understanding Institutional Diversity (Princeton, NJ: Princeton University Press, 2005).

Diekmann, Andreas. 1986. “Volunteer’s Dilemma: A Social Trap without a Dominant Strategy and Some Empirical Results.” In Paradoxical Effects of Social Behavior: Essays in Honor of Anatol Rapoport, ed. Andreas Diekmann and P. Mitter, 188-97. Vienna: Physica.

Dietz, Thomas, Elinor Ostrom, and Paul Stern. 2003. “The Struggle to Govern the Commons.” Science 302(5652): 1907-12.

Dolšak, Nives, and Elinor Ostrom. 2003. The Commons in the New Millennium. Cambridge, MA: MIT Press.

Ebenhöh, Eva and Claudia Pahl-Wostl. 2008. “Agent Behavior between Maximization and Cooperation.” Rationality and Society 20(2): 227-52. 
Eckel, Catherine C., and Philip Grossman. 1996. “Altruism in Anonymous Dictator Games.” Games and Economic Behavior 16(2): 181-91.

Ehrlich, Paul R., and Simon A. Levin. 2005. “The Evolution of Norms.” PLoS Biology 3(6): e194.

Falk, Armin, Ernst Fehr, and Urs Fischbacher. 2005. "Driving Forces behind Informal Sanctions.” Econometrica 73(6): 2017-30.

Faysse, Nicolas. 2005. "Coping with the Tragedy of the Commons: Game Structure and Design of Rules.” Journal of Economic Surveys 19(2): 239-61.

Fehr, Ernst, Urs Fischbacher, and Michael Kosfeld. 2005. "Neuroeconomic Foundations of Trust and Social Preferences: Initial Evidence.” American Economic Review 95(2): 346-51.

Fehr, Ernst, and Herbert Gintis. 2007. "Human Motivation and Social Cooperation: Experimental and Analytical Foundations.” Annual Review of Sociology 33: 43-64.

Fehr, Ernst, and Klaus Schmidt. 1999. “A Theory of Fairness, Competition, and Cooperation.” Quarterly Journal of Economics 114: 817-51.

Folke, Carl, Thomas Hahn, Per Olsson, and Jon Norberg. 2005. “Adaptive Governance of Social-Ecological Systems.” Annual Review of Environmental Resources 30: 441-73.

Frey, Bruno S. 1994. “How Intrinsic Motivation Is Crowded Out and In.” Rationality and Society 6(3):334-52.

Frey, Bruno S. 1997. “A Constitution for Knaves Crowds out Civic Virtue.” Economic Journal 107:1043-53.

Frohlich, Norman, and Joe Oppenheimer. 1992. Choosing Justice: An Experimental Approach to Ethical Theory. Berkeley: University of California Press.

Frohlich, Norman, and Joe Oppenheimer. 2000. "How People Reason about Ethics and the Role of Experiments: Content and Methods of Discovery.” In Elements of Political Reason: Cognition, Choice, and the Bounds of Rationality, ed. Arthur Lupia, Mathew D. McCubbins, and Samuel L. Popkin, 85-107. New York: Cambridge University Press.

Frohlich, Norman, Joe Oppenheimer, and Bernard J. Moore. 2001. "Some Doubts about Measuring Self-Interest Using Dictator Experiments: The Costs of Anonymity.” Journal of Economic Behavior and Organization 46(3): 271-90.

Gardner, Roy, and Elinor Ostrom. 1991. “Rules and Games.” Public Choice 70(2): 121-49.

Ghate, Rucha, Narpat Jodha, and P. Mukhopadhyay, eds. 2008. Promise, Trust, and Evolution: Managing the Commons of South Asia. Oxford: Oxford University Press. 
Ghate, Rucha, and Harini Nagendra. 2005. "The Role of Monitoring in Institutional Performance: Forest Management in Maharashtra, India.” Conservation and Society 3(2): 509-32.

Gibson, Clark, John Williams, and Elinor Ostrom. 2005. "Local Enforcement and Better Forests.” World Development 33(2): 273-84.

Gintis, Herbert. 2000. Game Theory Evolving: A Problem-Centered Introduction to Modeling Strategic Interaction. Princeton, NJ: Princeton University Press.

Goetze, David. 2008. "Public Goods, Sharing Genes, and the Formation of Large Groups.” Politics and the Life Sciences 26(2): 7-25.

Gordon, H. Scott. 1954. "The Economic Theory of a Common Property Resource: The Fishery.” Journal of Political Economy 62 (April): 124-42.

Gunderson, Lance H., and Lowell Pritchard, Jr., eds. 2002. Resilience and the Behavior of Large-Scale Systems. Washington, DC: Island Press.

Güth, Werner, and Steffen Huck. 1997. "From Ultimatum Bargaining to Dictatorship-An Experimental Study of Four Games Varying in Veto Power.” Metroeconomica 48(3): 262-99.

Hardin, Garrett. 1968. “The Tragedy of the Commons.” Science 162: 1243-48.

Hayashi, Nahoko, and Arinori Yosano. 2005. "Trust and Belief about Others: Focusing on Judgment Accuracy of Others’ Trustworthiness.” Sociological Theory and Methods 37: 59-80.

Hayes, Tanya. 2006. "Parks, People, and Forest Protection: An Institutional Assessment of the Effectiveness of Protected Areas.” World Development 34(12): 2064-75.

Henrich, Joseph, et al. 2006. “Costly Punishment across Human Societies.” Science 312 (June 23): 1767-70.

Hoffman, Elizabeth, Kevin McCabe, K. Shachat, and Vernon L. Smith. 1994. "Preferences, Property Rights, and Anonymity in Bargaining Games.” Games and Economic Behavior 7: 346-80.

Hoffman, Elizabeth, Kevin McCabe, and Vernon L. Smith. 1996. "Social Distance and OtherRegarding Behavior in Dictator Games.” American Economic Review 86(3): 653-60.

Isaac, R. Mark, and James M. Walker. 1998. "Nash as an Organizing Principle in the Voluntary Provision of Public Goods: Experimental Evidence.” Experimental Economics 1: 191206. 
Isaac, R. Mark, James M. Walker, and Arlington Williams. 1994. "Group Size and the Voluntary Provision of Public Goods: Experimental Evidence Utilizing Large Groups.” Journal of Public Economics 54(1) (May): 1-36.

Janssen, Marco A. 2008. "Evolution of Cooperation in a One-Shot Prisoner's Dilemma Based on Recognition of Trustworthy and Untrustworthy Agents.” Journal of Economic Behavior and Organization 65: 458-71.

Janssen, Marco, Robert Goldstone, Filippo Menczer, and Elinor Ostrom. 2008. "Effect of Rule Choice in Dynamic Interactive Spatial Commons." International Journal of the Commons 2(2): 288-312.

Janssen, Marco, and Elinor Ostrom. 2006. “Adoption of a New Regulation for the Governance of Common-Pool Resources by a Heterogeneous Population.” In Inequality, Cooperation, and Environmental Sustainability, ed. Jean-Marie Baland, Pranab Bardhan, and Samuel Bowles, 60-96. Princeton, NJ: Princeton University Press.

Janssen, Marco, and Elinor Ostrom. Forthcoming. "TURFS in the Lab: Institutional Innovation in Real-Time Dynamic Spatial Commons.” Rationality and Society.

Kaimowitz, David, and Arild Angelsen. 1998. Economic Models of Tropical Deforestation: A Review. Bogor, Indonesia: Center for International Forestry Research.

Keser, Claudia. 2003. "Experimental Games for the Design of Reputation Management Systems.” IBM Systems Journal 42: 498-506.

Kikuchi, Masao, Yoriko Watanabe, and Toshio Yamagishi. 1996. "Accuracy in the Prediction of Others’ Trustworthiness and General Trust: An Experimental Study.” Japanese Journal of Experimental Social Psychology 37(1): 23-36.

Lave, Lester B. 1965. “Factors Affecting Cooperation in the Prisoner’s Dilemma.” Behavioral Science 10: 26-35.

Levin, Simon A. 1999. Fragile Dominion: Complexity and the Commons. Reading, MA: Perseus Books.

Macy, Michael W., and John Skvoretz. 1998. "The Evolution of Trust and Cooperation between Strangers: A Computational Model.” American Sociological Review 63: 638-60.

Masters, Roger D. 2008. "Historical Change and Evolutionary Theory.” Politics and the Life Sciences 26(1): 46-74.

Maynard Smith, John. 1982. Evolution and the Theory of Games. Cambridge: Cambridge University Press. 
Maynard Smith, John, and Eörs Szathmáry. 1997. The Major Transitions in Evolution. Oxford: Oxford University Press.

McCabe, Kevin, and Vernon Smith. 2001. “Goodwill Accounting in Economic Exchange.” In Bounded Rationality: The Adaptive Tool Box, ed. Gerd Gigerenzer and Reinhard Selten, 319-42. Cambridge, MA: MIT Press.

McCay, Bonnie J., and James M. Acheson. 1987. The Question of the Commons: The Culture and Ecology of Communal Resources. Tucson: University of Arizona Press.

Moran, Emilio, and Elinor Ostrom. 2005. Seeing the Forest and the Trees. Cambridge, MA: MIT Press.

Mwangi, Esther. 2007. Socioeconomic Change and Land Use in Africa: The Transformation of Property Rights in Maasailand. New York: Palgrave Macmillan.

Myers, Ransom A., and Boris Worm. 2003. "Rapid Worldwide Depletion of Predatory Fish Communities.” Nature 423 (May 15): 280-83.

NRC (National Research Council). 1986. Proceedings of the Conference on Common Property Resource Management. Washington, DC: National Academy Press.

NRC (National Research Council). 2002. The Drama of the Commons. Committee on the Human Dimensions of Global Change. Elinor Ostrom, Thomas Dietz, Nives Dolšak, Paul Stern, Susan Stonich, and Elke Weber, eds. Washington, DC: National Academy Press.

Ostrom, Elinor. 1990. Governing the Commons: The Evolution of Institutions for Collective Action. New York: Cambridge University Press.

Ostrom, Elinor. 1998. “A Behavioral Approach to the Rational Choice Theory of Collective Action.” American Political Science Review 92(1): 1-22.

Ostrom, Elinor. 2003. “Toward a Behavioral Theory Linking Trust, Reciprocity, and Reputation.” In Trust and Reciprocity: Interdisciplinary Lessons from Experimental Research, ed. Elinor Ostrom and James Walker, 19-79. New York: Russell Sage Foundation.

Ostrom, Elinor. 2005. Understanding Institutional Diversity. Princeton, NJ: Princeton University Press.

Ostrom, Elinor. 2007. “A Diagnostic Approach for Going Beyond Panaceas.” Proceedings of the National Academy of Sciences 104(39): 15181-87.

Ostrom, Elinor. 2008. “The Challenge of Common-Pool Resources.” Environment 50(4) (July/August): 8-20. 
Ostrom, Elinor, Roy Gardner, and James Walker, 1994. Rules, Games, and Common-Pool Resources. Ann Arbor: University of Michigan Press.

Ostrom, Elinor, and Harini Nagendra. 2006. "Insights on Linking Forests, Trees, and People from the Air, on the Ground, and in the Laboratory.” PNAS 103(51): 19224-31.

Ostrom, Elinor, and James Walker. 1991. "Communication in a Commons: Cooperation without External Enforcement.” In Laboratory Research in Political Economy, ed. Thomas R. Palfrey, 287-322. Ann Arbor: University of Michigan Press.

Ostrom, Elinor, James Walker, and Roy Gardner. 1992. "Covenants with and without a Sword: Self-Governance is Possible.” American Political Science Review 86(2): 404-17.

Pauly, D., et al. 2002. “Toward Sustainability in World Fisheries.” Nature 418: 689-95.

Poteete, Amy, and Elinor Ostrom. 2004. "Heterogeneity, Group Size and Collective Action: The Role of Institutions in Forest Management.” Development and Change 35(3): 435-61.

de Quervain, Dominique J.-F., et al. 2004. “The Neural Basis of Altruistic Punishment.” Science 305 (August 27): 1254-58.

Rapoport, Anatol, and A. M. Chummah. 1965. Prisoners’ Dilemma: A Study of Conflict and Cooperation. Ann Arbor: University of Michigan Press.

Richards, Diana. 2001. "Reciprocity and Shared Knowledge Structures in a Prisoner’s Dilemma Game.” Journal of Conflict Resolution 45: 621-35.

Richards, Kenneth, and Krister Andersson. 2001. "The Leaky Sink: Persistent Obstacles to a Forest Carbon Sequestration Program Based on Individual Projects.” Climate Policy 1: 41-54.

Rilling, James K., David A. Gutman, Thorsten R. Zeh, Giuseppe Pagnoni, Gregory S. Berns, and Clinton D. Kilts. 2002. “A Neural Basis for Social Cooperation.” Neuron 35(2): 395-405.

Rodriguez-Sickert, Carlos, Ricardo Andrés Guzmán, and Juan Camilo Cárdenas. 2008. "Institutions Influence Preferences: Evidence from a Common-Pool Resource Experiment.” Journal of Economic Behavior and Organization 67(1): 215-27.

Rudel, Thomas K. 2005. Tropical Forests: Regional Paths of Destruction and Regeneration in the Late Twentieth Century. New York: Colombia University Press.

Sally, David. 1995. "Conversation and Cooperation in Social Dilemmas: A Meta-Analysis of Experiments from 1958 to 1992.” Rationality and Society 7: 58-92.

Satz, D., and John Ferejohn. 1994. "Rational Choice and Social Theory.” Journal of Philosophy 91(2): 71-87. 
Schlager, Edella, and Elinor Ostrom. 1992. "Property-Rights Regimes and Natural Resources: A Conceptual Analysis.” Land Economics 68(3): 249-62.

Shivakumar, Sujai. 2005. The Constitution of Development: Crafting Capabilities for SelfGovernance. New York: Palgrave Macmillan.

Simon, Adam, and David Schwab. 2006. "Say the Magic Word: Effective Communication in Social Dilemmas.” Working Paper. Bloomington: Indiana University, Workshop in Political Theory and Policy Analysis.

Skyrms, Brian. 1997. "Chaos and the Explanatory Significance of Equilibrium: Strange Attractors in Evolutionary Game Dynamics.” In The Dynamics of Norms, ed. Cristina Bicchieri, Richard Jeffrey, and Brian Skyrms, 199-222. Cambridge: Cambridge University Press.

Xepapadeas, Anastasios. 2005. "Regulation and Evolution of Compliance in Common Pool Resources.” Scandinavian Journal of Economics 107(3): 583-99.

Yamagishi, Toshio, and M. Kosugi. 1999. “Character Detection in Social Exchange.” Cognitive Studies 6(2): 179-90. 


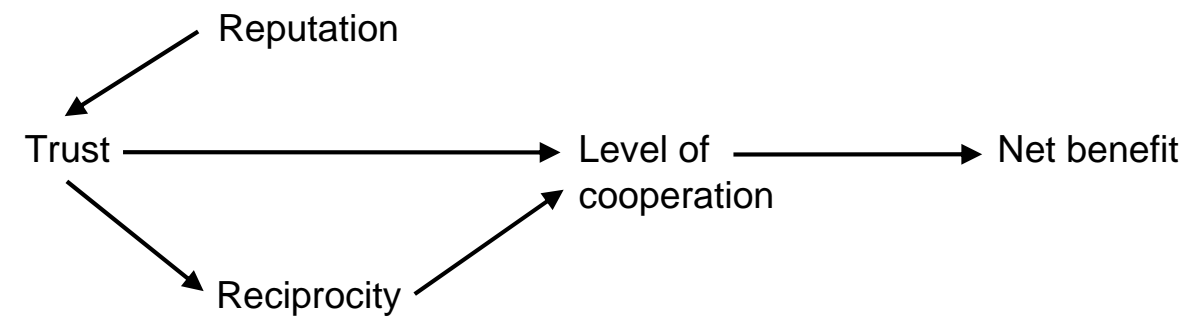

Figure 1. The core relationships in repeated social dilemmas

Source: Adapted from Ostrom (1998: 13). 


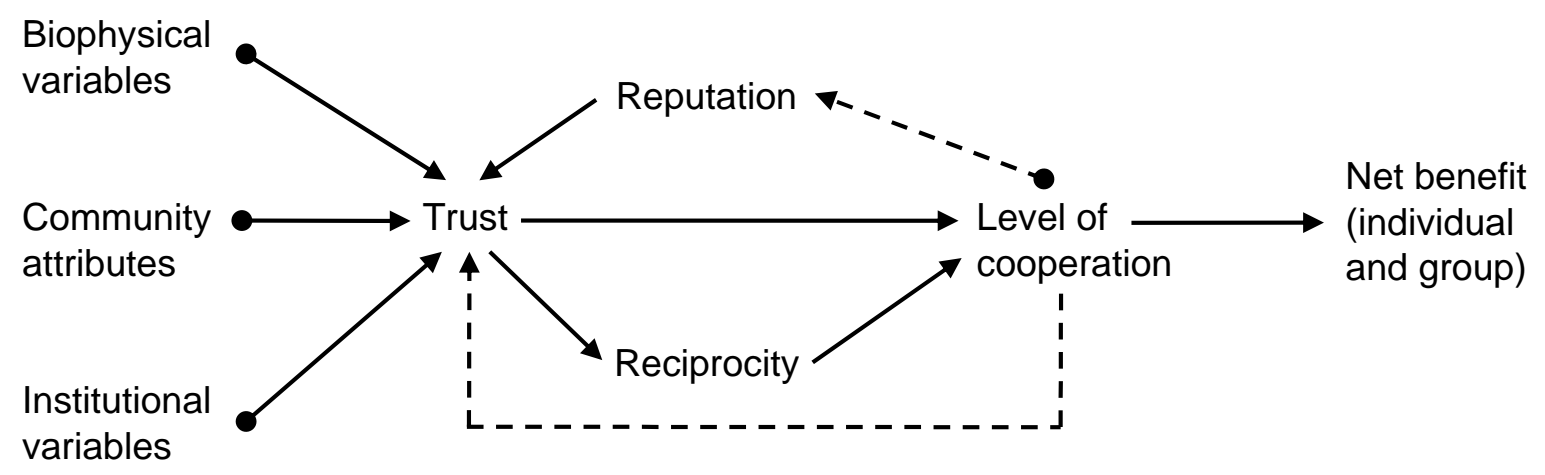

Figure 2. Context and feedback in repeated social dilemmas

Source: Adapted from Ostrom and Walker (2003: 51). 


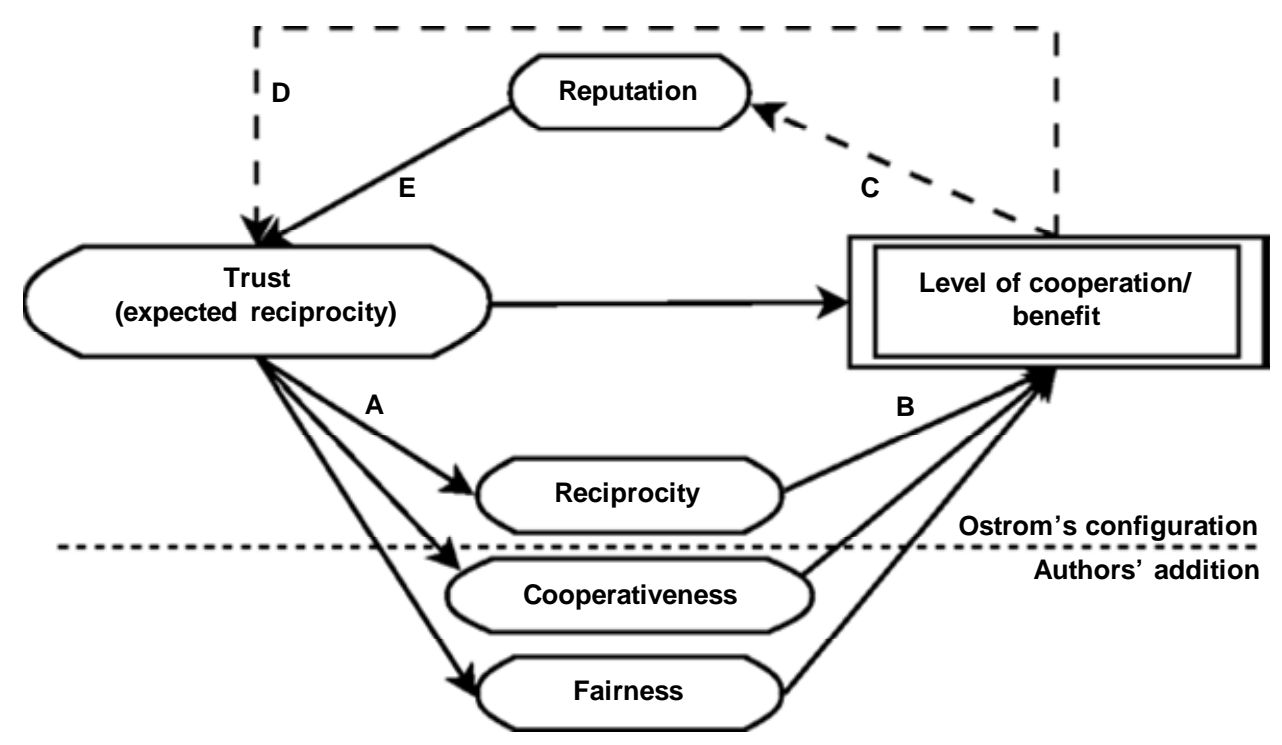

Figure 3. Adapted and extended from Ostrom (2004: 51). High trust enhances reciprocity $(A)$, cooperativeness, and fairness. High reciprocity enhances cooperation in a group and therefore the benefit in a social dilemma (B), which in turn creates a good reputation (C) and increases trust (D). If a good reputation is established, this also increases trust (E). Dashed arrows indicate the feedback of previous interactions within a group.

Source: Ebenhöh and Pahl-Wostl (2008: 231). 